\title{
Electrochemical Capacitors Using Fluorohydrogenate Ionic Liquid Electrolytes
}

\section{AUTHOR(S):}

Matsumoto, Kazuhiko; Takahashi, Kenji; Senda, Atsushi; Nohira, Toshiyuki; Hagiwara, Rika

\section{CITATION:}

Matsumoto, Kazuhiko ...[et al]. Electrochemical Capacitors Using Fluorohydrogenate Ionic Liquid Electrolytes. ECS Transactions 2019, 33(7): 421-427

\section{ISSUE DATE:}

2019-12-17

URL:

http://hdl.handle.net/2433/259811

\section{RIGHT:}

(c) The Electrochemical Society, Inc. 2019. All rights reserved. Except as provided under U.S. copyright law, this work may not be reproduced, resold, distributed, or modified without the express permission of The Electrochemical Society (ECS). The archival version of this work was published in 'ECS Transactions' 33(7), 421-427; この論文は出版社版であり ません。引用の際には出版社版をご確認じ利用ください。; This is not the published version. Please cite only the published version. 


\title{
Electrochemical Capacitors Using Fluorohydrogenate Ionic Liquid Electrolytes
}

\author{
Kazuhiko Matsumoto, Kenji Takahashi, Atsushi Senda, Toshiyuki Nohira, \\ Rika Hagiwara \\ Graduate School of Energy Science, Kyoto University \\ Kyoto 606-8501, JAPAN
}

\begin{abstract}
Electrochemical capacitors using fluorohydrogenate ionic liquids show a large voltage dependence of capacitance with a maximum at a charging voltage around $2.5 \mathrm{~V}$, resulting in a larger capacitance than those using other typical ionic liquid electrolytes. The voltage dependence becomes less remarkable with decrease in the $\mathrm{HF}$ composition $n$ in $\operatorname{EMIm}(\mathrm{FH})_{n} \mathrm{~F}$ (EMIm: 1-ethyl-3methylimidazolium). Cyclic voltammetry using an activated carbon working electrode revealed that two redox reactions occur at the higher and lower potentials against the rest potential in $\operatorname{EMIm}(\mathrm{FH})_{2.3} \mathrm{~F}$. These Faradaic processes contribute to the voltage dependence of capacitance.
\end{abstract}

\section{Introduction}

Electrochemical capacitors are attractive energy storage devices because of their high power density and long lifetime (1) and can be classified into several types such as double-layer capacitor and redox capacitor, depending on the mechanism of energy storage. Activated carbon electrodes with a large surface area are usually used in doublelayer capacitors since energy is stored at the interface between the electrode surface and the electrolytic solution without Faradaic reactions.

The higher achievable voltage for nonaqueous electrolytes $(\sim 3 \mathrm{~V})$ compared to that for aqueous electrolytes $(\sim 1 \mathrm{~V})$ is a great benefit to construct electrochemical capacitors with a large energy density, whereas their low conductivity increases the internal resistance. From the viewpoint of safety, flammability of the organic electrolytes is another drawback especially for their application to large-scale capacitors. Ionic liquids (ILs) have some unique properties including nonflammability and low vapor pressure and are potential electrolytes to replace the electrolytes in the present electrochemical devices $(2,3)$. Fluorohydrogenate ILs contain fluorohydrogenate anion $(\mathrm{FH})_{n} \mathrm{~F}^{-}$as anionic species and exhibit a high ionic conductivity, low viscosity, and low melting point compared to other ILs (conductivity: $100 \mathrm{mS} \mathrm{cm}{ }^{-1}$ (at $298 \mathrm{~K}$ ), viscosity: $4.9 \mathrm{cP}$ (at $298 \mathrm{~K}$ ), and melting point: $208 \mathrm{~K}$ for $\mathrm{EMIm}(\mathrm{FH})_{2.3} \mathrm{~F}$ (EMIm = 1-ethyl-3-methylimidazolium)) $(4,5)$. The ratio of the anions, $\mathrm{FHF}^{-},(\mathrm{FH})_{2} \mathrm{~F}^{-}$, and $(\mathrm{FH})_{3} \mathrm{~F}^{-}$is determined by the HF composition number $n$, and the vacuum-stable maximum composition $n$ is 2.3 at $298 \mathrm{~K}$ in most cases regardless of the cationic structures (6-8). This HF composition number $n$ in nonvolatile fluorohydrogenate ILs can be controlled in the range between 1.0 and 2.3 by removing $\mathrm{HF}$ at elevated temperatures (9). A recent study on the application of fluorohydrogenate ILs having five different cationic structures (three imidazolium-based and two pyrrolidinium-based cations) as electrolytes in electrochemical capacitors revealed that the capacitance of these capacitors is larger than those using other ILs such as EMImBF 4 
(10). They exhibit a significant voltage dependence of capacitance with a maximum around $2.5 \mathrm{~V}$, whereas the capacitance drops steeply at higher charging voltages because of decomposition of the electrolyte. For some fluorohydrogenate ILs having a melting point lower than $233 \mathrm{~K}$, charge-discharge cycles at low temperatures (233-298 K) were successfully performed. This work reports details on electrochemical behavior of activated carbon electrodes in fluorohydrogenate ILs to elucidate the large voltage dependence of capacitance.

\section{Experimental}

\section{$\underline{\text { Synthesis }}$}

The electrolyte, $\mathrm{EMIm}(\mathrm{FH})_{2.3} \mathrm{~F}$, was prepared by the reaction of $\mathrm{EMImCl}$ and excess anhydrous $\mathrm{HF}$ as reported in the literature $(4,5)$. The fluorohydrogenate IL with a smaller $n$, EMIm $(\mathrm{FH})_{1.8} \mathrm{~F}$, was prepared by removing $\mathrm{HF}$ at $348 \mathrm{~K}$ for 6 days. The $\mathrm{HF}$ composition was confirmed by elemental analysis and titration with an aqueous $\mathrm{NaOH}$ solution. The EMImBF 4 IL electrolyte was purchased from Kanto Kagaku and dried under vacuum $(<1 \mathrm{~Pa})$ at $373 \mathrm{~K}$ for two days.

\section{Electrochemical measurements}

Electrochemical measurements were performed at $298 \mathrm{~K}$ with the aid of an electrochemical measurement system HZ-3000 (Hokuto Denko). For a three-electrode test, activated carbon sheet $[0.5 \mathrm{~mm}$ in thickness, $85 \mathrm{wt} \%$ of activated carbon from phenol resin (surface area: $2000 \mathrm{~m}^{2} \mathrm{~g}^{-1}$ ), $10 \mathrm{wt} \%$ of PTFE, and $5 \mathrm{wt} \%$ of carbon black] was cut into a piece $(\sim 10 \mathrm{mg})$ and fixed on a vitreous carbon lead. The reference electrode was made of silver wire immersed in $\mathrm{EMImBF}_{4}$ containing $0.05 \mathrm{M} \mathrm{AgBF}_{4}$ that was separated from the electrolyte by a window made of porous Vycor glass. Activated carbon (the same spec as that of the working electrode) was used as a counter electrode.

A two-electrode cell made of PTFE was used for charge-discharge tests. A pair of activated carbon sheets (the same spec as for the three-electrode test) with a diameter of $10 \mathrm{~mm}$ and $21 \mathrm{mg}$ per each was used in this case. The electrodes dried under vacuum at $453 \mathrm{~K}$ overnight are immersed in the electrolyte and degassed under vacuum before use. The PTFE filter (ADVANTEC H100A013A, $35 \mu \mathrm{m}$ in thickness and $13 \mathrm{~mm}$ in diameter) was used as a separator. Vitreous carbon disks were used as current collectors.

\section{Results and Discussion}

Figure 1 shows the structures of $\mathrm{EMIm}^{+}, \mathrm{FHF}^{-},(\mathrm{FH})_{2} \mathrm{~F}^{-}$, and $(\mathrm{FH})_{3} \mathrm{~F}^{-}$. The two fluorohydrogenate ILs, $\operatorname{EMIm}(\mathrm{FH})_{2.3} \mathrm{~F}$ and $\operatorname{EMIm}(\mathrm{FH})_{1.8} \mathrm{~F}$, are used as electrolytes in the current study, where $\operatorname{EMIm}(\mathrm{FH})_{2.3} \mathrm{~F}$ contains $(\mathrm{FH})_{2} \mathrm{~F}^{-}$and $(\mathrm{FH})_{3} \mathrm{~F}^{-}$in the ratio of 7 to 3 and $\mathrm{EMIm}(\mathrm{FH})_{1.8} \mathrm{~F}$ contains $\mathrm{FHF}^{-}$and $(\mathrm{FH})_{2} \mathrm{~F}^{-}$in the ratio of 2 to $8(9)$.

Figure 2 shows voltage dependence of capacitance obtained for $\operatorname{EMIm}(\mathrm{FH})_{2.3} \mathrm{~F}$ and $\mathrm{EMIm}(\mathrm{FH})_{1.8} \mathrm{~F}$ together with those of $\mathrm{EMImBF}_{4}$. Fluorohydrogenate ionic liquids show a significant voltage dependence of capacitance as reported in the previous study. Capacitance decreases with decreasing the HF composition $n$ from 2.3 to 1.8 at all the charging voltages, suggesting the anion plays an important role in the high capacitance. Nevertheless, the capacitance observed for $\operatorname{EMIm}(\mathrm{FH})_{1.8} \mathrm{~F}$ is still higher than that for 
EMImBF 4 . The maximum capacitance for $\operatorname{EMIm}(\mathrm{FH})_{1.8} \mathrm{~F}$ is $69 \%$ of that for $\operatorname{EMIm}(\mathrm{FH})_{2.3} \mathrm{~F}$. It should be noted that the voltage where the maximum capacitance is attained is reduced by decreasing $n$.

(a)

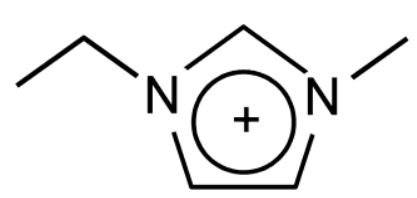

(c)
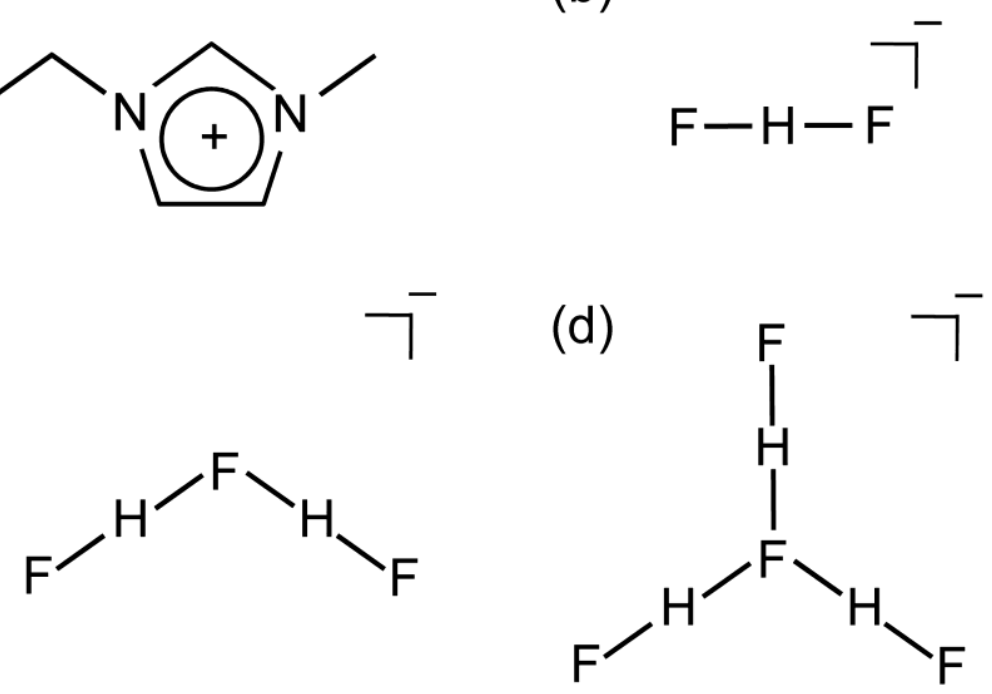

(b)

Figure 1. The structures of $\mathrm{EMIm}^{+}, \mathrm{FHF}^{-},(\mathrm{FH})_{2} \mathrm{~F}^{-}$, and $(\mathrm{FH})_{3} \mathrm{~F}^{-}$.

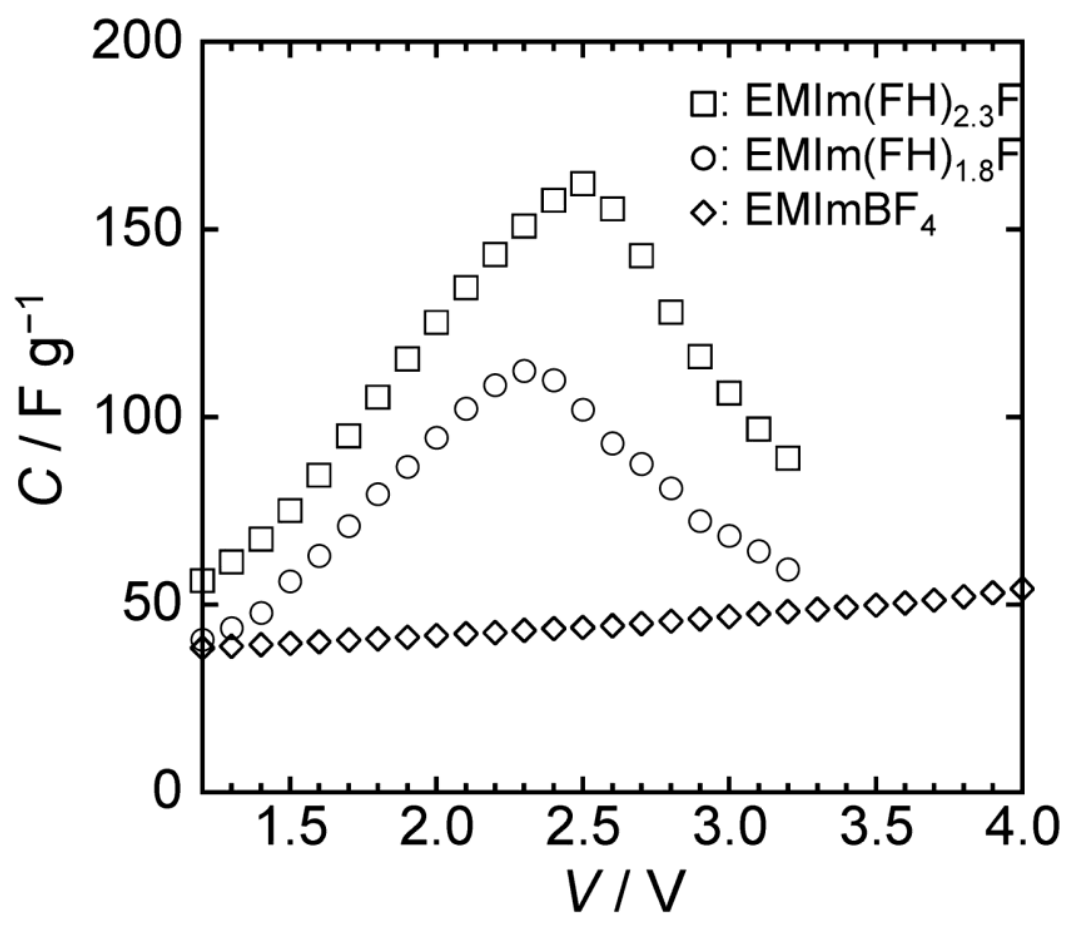

Figure 2. Voltage dependence of capacitance for the capacitors using $\operatorname{EMIm}(\mathrm{FH})_{2.3} \mathrm{~F}$, $\mathrm{EMIm}(\mathrm{FH})_{1.8} \mathrm{~F}$, and $\mathrm{EMImBF}_{4}$. The capacitor cell was charged and kept by a constant voltage mode at a given voltage for one hour and discharged by a constant current mode to $0 \mathrm{~V}$ at a current of $5 \mathrm{~mA}$. Both the positive and negative electrodes weigh $21 \mathrm{mg}$. 
Figure 3 shows discharge curves for $\mathrm{EMIm}(\mathrm{FH})_{2.3} \mathrm{~F}$ and $\mathrm{EMImBF}_{4}$. For $\mathrm{EMImBF}_{4}$, the voltage decreases linearly from the given voltage to $0 \mathrm{~V}$ and the discharge curves are, roughly speaking, parallel to each other. This behavior reflects the small voltage dependence of capacitance for $\mathrm{EMImBF}_{4}$ as shown in Figure 2. The discharge curve for $\operatorname{EMIm}(\mathrm{FH})_{2.3} \mathrm{~F}$ is also linear at the charging voltage of $1.5 \mathrm{~V}$. In the cases of the charging voltages of 2.0 and $2.5 \mathrm{~V}$, the slope of the discharge curve gradually becomes gentle and the discharge curve is almost linear after ten minutes. The slopes of the linear regions in the three discharges curves are not parallel to each other, resulting in the large voltage dependence of capacitance in Figure 2.

(a)

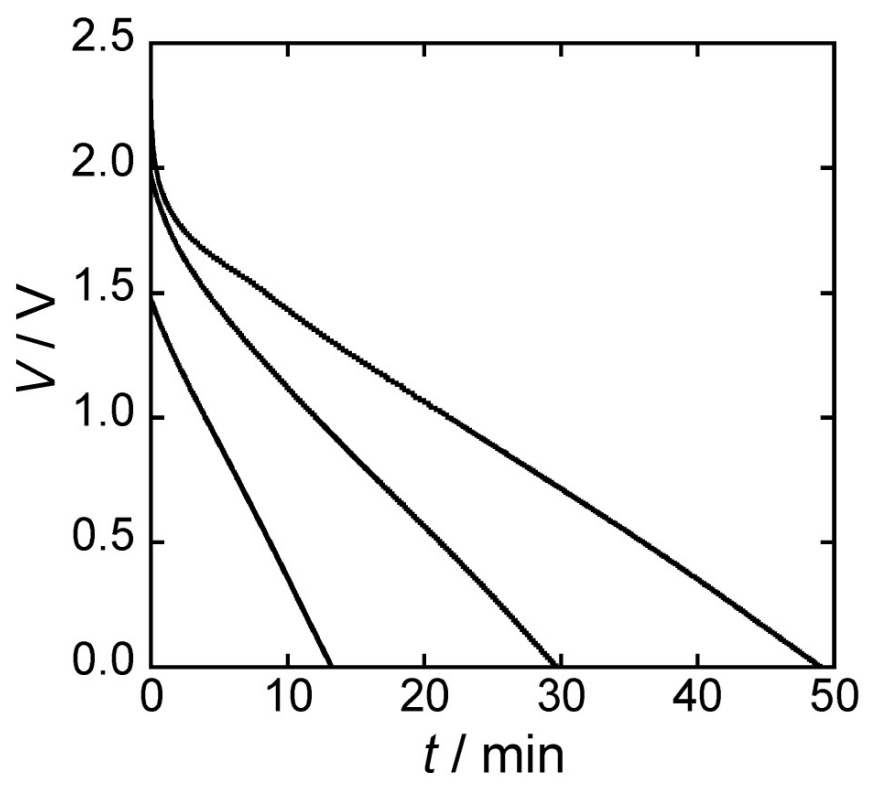

(b)

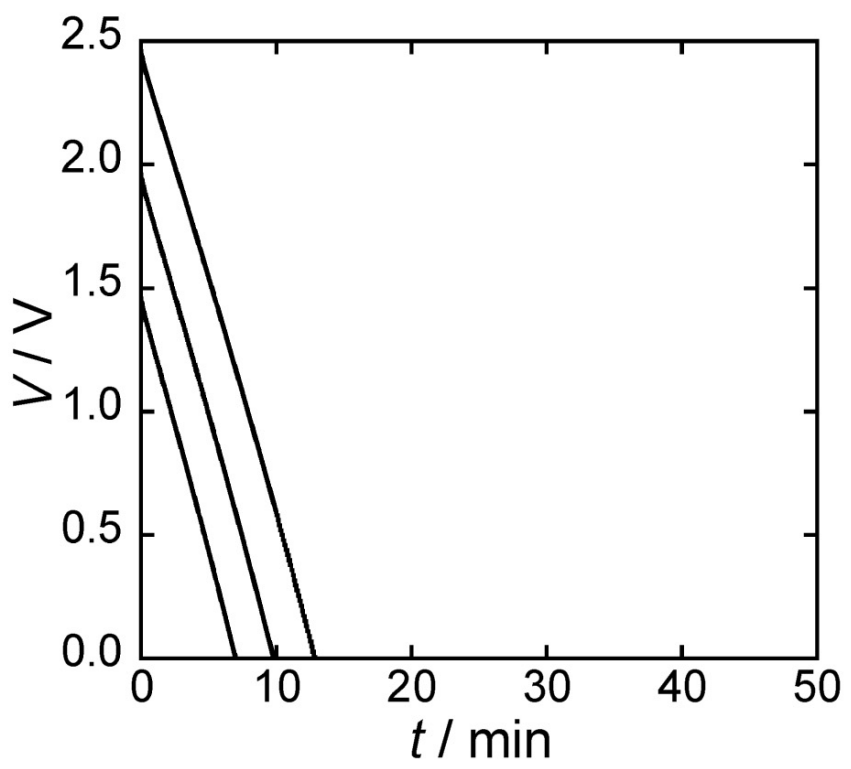

Figure 3. Discharge curves of the capacitors using (a) $\operatorname{EMIm}(\mathrm{FH})_{2.3} \mathrm{~F}$ and (b) $\mathrm{EMImBF}_{4}$. See the caption of Figure 2 for the experimental conditions. 
Figure 4 shows the retention rate of capacitance in the first 10 cycles for the capacitor using $\operatorname{EMIm}(\mathrm{FH})_{2.3} \mathrm{~F}$ at the charging voltages of 2.0, 2.1, 2.2, 2.3 and $2.5 \mathrm{~V}$. The retention rate reaches the maximum at the second or third cycle in any case and declines after that. The decline in retention rate is gentle at the charging voltage of 2.0 and $2.1 \mathrm{~V}$ and increase in charging voltage $(>2.2 \mathrm{~V})$ accelerates the decline, which suggests that decomposition of the electrolyte occurs at the voltage more than $2.2 \mathrm{~V}$. This result suggests that the voltage where the maximum capacitance is observed in Figure 2 does not directly correspond to the breaking-up voltage since the capacitance in Figure 2 is calculated from the result of one charge-discharge cycle and does not reflect the longterm stability. The capacitance for $\operatorname{EMIm}(\mathrm{FH})_{2.3} \mathrm{~F}$ at higher than $2.2 \mathrm{~V}$ may be determined by the balance of several factors including increase of capacitance and deterioration of the electrolyte.

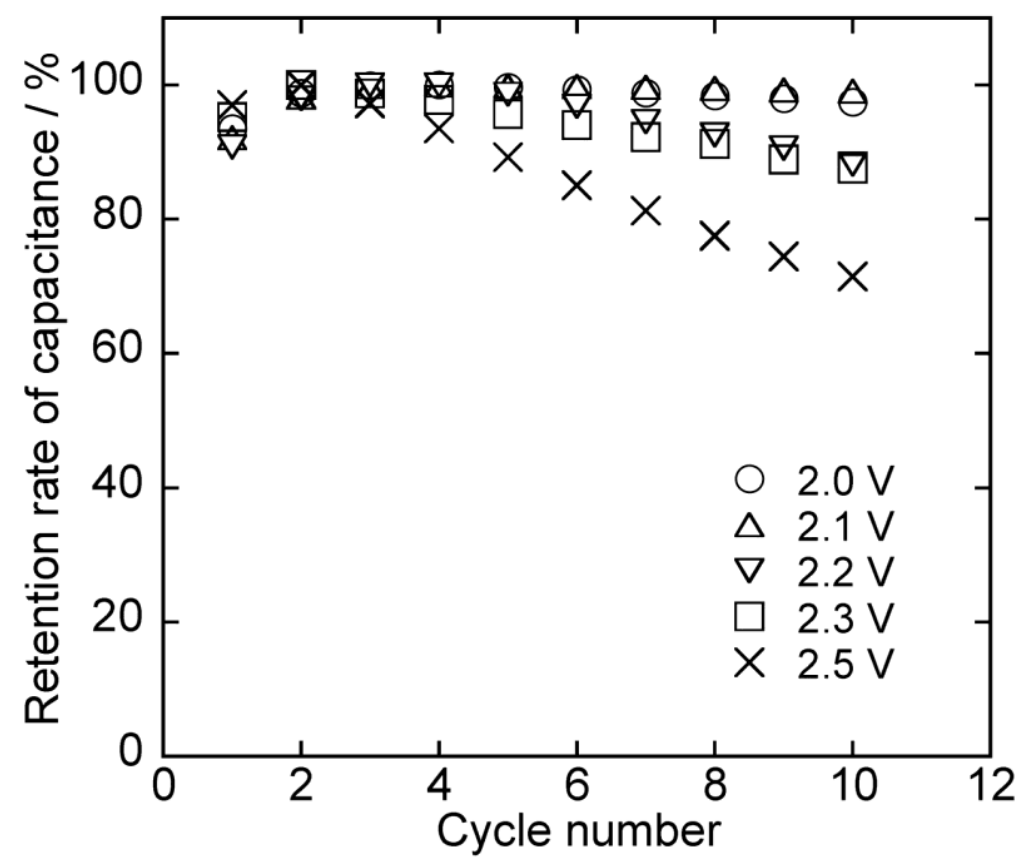

Figure 4 Retention rate of capacitance in the first 10 cycles for the capacitor using $\mathrm{EMIm}(\mathrm{FH})_{2.3} \mathrm{~F}$ at the charging voltages of $2.0,2.1,2.2$, and $2.5 \mathrm{~V}$.

Figure 5 shows cyclic voltammograms of an activated carbon electrode in (a) $\operatorname{EMIm}(\mathrm{FH})_{2.3} \mathrm{~F}$ and (b) $\mathrm{EMImBF}_{4}$. For $\mathrm{EMImBF}_{4}$, the activated carbon electrode exhibits the typical behavior as an electrode in capacitors without an apparent Faradaic reaction in this range. For $\operatorname{EMIm}(\mathrm{FH})_{2.3} \mathrm{~F}$, the cathodic sweep from the rest potential $(\sim-0.3 \mathrm{~V})$ results in a reduction wave from $-1.0 \mathrm{~V}$, followed by the anodic sweep giving the corresponding anodic wave from $-0.5 \mathrm{~V}$. The position of the anodic wave shifts towards the higher potential as the reversing potential becomes lower. According to a previous report (5), the cathodic limit of $\mathrm{EMIm}(\mathrm{FH})_{2.3} \mathrm{~F}$ measured on a vitreous carbon electrode is $\sim-1.9 \mathrm{~V}$ vs. $\mathrm{Fc}^{+} / \mathrm{Fc}$, whereas the lower overpotential of hydrogen gas evolution on a $\mathrm{Pt}$ electrode results in a higher cathodic limit potential of $-1.2 \mathrm{~V}$ vs. $\mathrm{Fc}^{+} / \mathrm{Fc}$. In the present case, the cathodic wave is considered to be the reduction of $(\mathrm{FH})_{n} \mathrm{~F}^{-}$, taking the case of the Pt electrode into account. The reduced species may be hydrogen atoms adsorbed on the electrode since the reversible reaction occurs in the cyclic voltammogram. The sweep to the higher potential against the rest potential gives another anodic wave rising from 0 
$\mathrm{V}$. This reaction might be assigned to fluorination of the surface functional groups on the activated carbon electrode. Although intercalation of fluorine atom is excluded in this case because of the poor layered structure of activated carbon, absorption of small fluorine atoms between disordered layers is another possible reason for this redox wave. These two redox waves are thought to contribute to the large voltage dependence of capacitance in Figure 2.

(a)

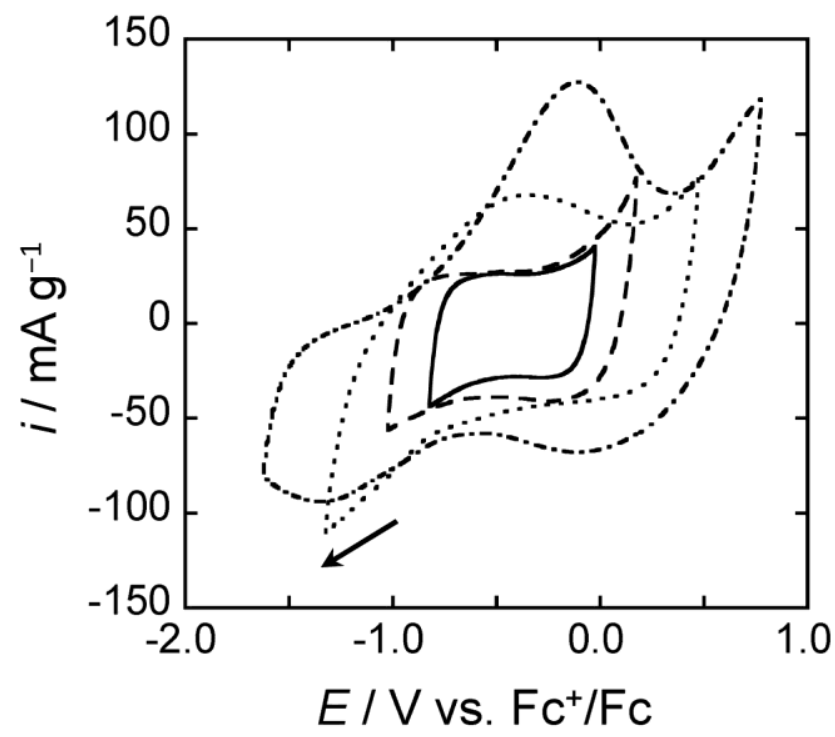

(b)

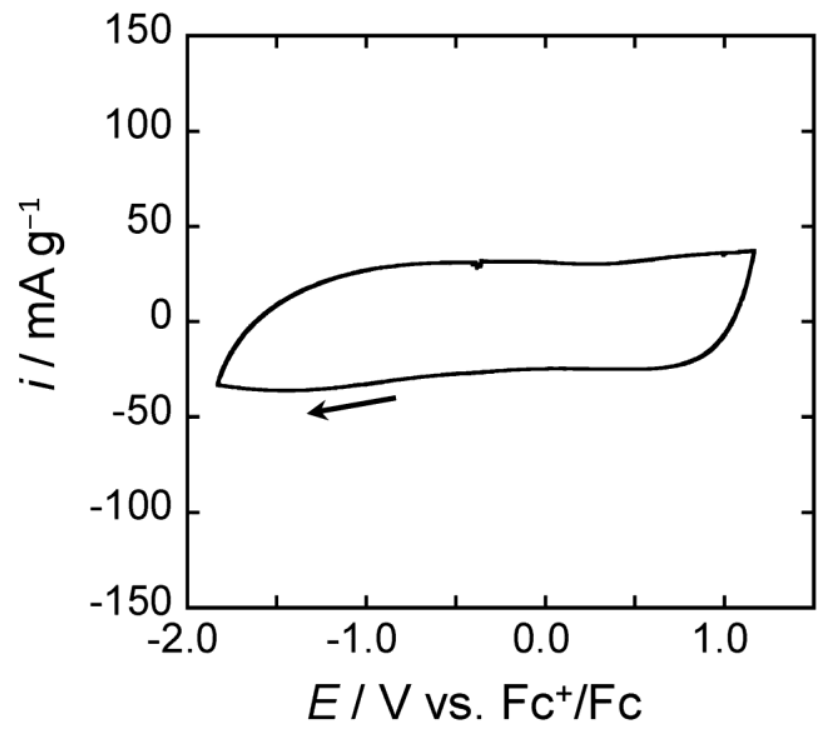

Figure 5 Cyclic voltammograms of an activated carbon electrode in (a) $\operatorname{EMIm}(\mathrm{FH})_{2.3} \mathrm{~F}$ and (b) $\mathrm{EMImBF}_{4}$. Scan rate: $0.2 \mathrm{mV} \mathrm{s}^{-1}$.

\section{Acknowledgments}

This work was financially supported by the Grant-in-Aid for Scientific Research of Japan Society for the Promotion of Science, \#20246140. 


\section{References}

1. B. E. Conway, Electrochemical Supercapacitors, Kluwer Academic/Plenum Publishers, New York (1999).

2. H. Ohno, Electrochemical Aspects of Ionic Liquids, John Wiley and Sons, Inc., Hooken (2005).

3. R. Hagiwara, Electrochemistry, 70, 130 (2002).

4. R. Hagiwara, T. Hirashige, T. Tsuda, and Y. Ito, J. Electrochem. Soc., 149, D1 (2002).

5. R. Hagiwara, K. Matsumoto, Y. Nakamori, T. Tsuda, Y. Ito, H. Matsumoto, and K. Momota, J. Electrochem. Soc., 150, D195 (2003).

6. K. Matsumoto, R. Hagiwara, and Y. Ito, Electrochem. Solid-State Lett., 7, E41 (2004).

7. S. Kanematsu, K. Matsumoto, and R. Hagiwara, Electrochem. Commun., 11, 1312 (2009).

8. M. Yamagata, S. Konno, K. Matsumoto, and R. Hagiwara, Electrochem. SolidState Lett., 12, F9 (2009).

9. R. Hagiwara, Y. Nakamori, K. Matsumoto, and Y. Ito, J. Phys. Chem. B, 109, 5445 (2005).

10. A. Senda, K. Matsumoto, T. Nohira, and R. Hagiwara, J. Power Sources, 195, 4414 (2010). 